Carlos Eduardo Coradassi

Fabiana Postiglione Mansani

Felicio de Freitas Netto

Gabriela Benassi

Lislei Teresinha Preuss

Pollyanna Kássia de Oliveira Borges

Ricardo Zanetti Gomes

\title{
MANEJO DA INFECÇÃO PELO NOVO CORONAVIRUS: DA ATENÇÃO PRIMÁRIA AOS SERVIÇOS HOSPITALARES
}

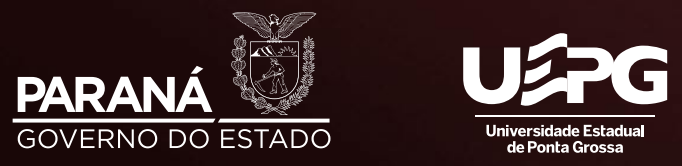




\title{
GOVERNO DO ESTADO DO PARANÁ
}

\author{
Governador \\ Carlos Massa Ratinho Júnior \\ Vice-governador \\ Darci Piana \\ Superintendência Geral de Ciência, Tecnologia e \\ Ensino Superior \\ Aldo Nelson Bona
}

UNIVERSIDADE ESTADUAL DE PONTA GROSSA

\author{
Reitor \\ Miguel Sanches Neto \\ Vice-reitor \\ Everson Augusto Krum
}

Pró-reitoria de Extensão e Assuntos Culturais

Clóris Regina Blanski Grden

Programa UEPG de Apoio Institucional para Ações Extensionistas de Prevenção, Cuidados e Combate à Pandemia do Novo Coronavírus

Pollyanna Kássia de Oliveira Borges 
\#uepgcontra ocoronavírus

Carlos Eduardo Coradassi

Fabiana Postiglione Mansani

Felício de Freitas Netto

Gabriela Benassi

Lislei Teresinha Preuss

Pollyanna Kássia de Oliveira Borges

Ricardo Zanetti Gomes

\section{MANEJO DA INFECÇÃO PELO NOVO CORONAVÍRUS: DA ATENÇÃO PRIMÁRIA AOS SERVIÇOS HOSPITALARES}

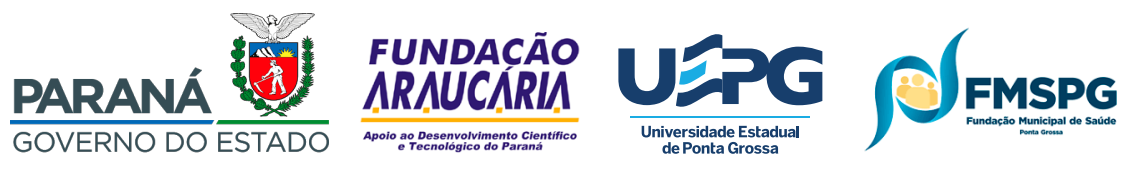




\section{PROEX UEPG}

\section{Equipe Editorial}

\section{Revisão de língua portuguesa \\ Emilson Richard Werner}

\section{Imagem da capa}

Freepik

\section{Diagramação}

Marco Aurélio Martins Wrobel

\section{Apoio}

Editora UEPG

M274 Manejo da infecção pelo novo coronavírus: da atenção primária aos serviços hospitalares [livro eletrônico]/ Carlos Eduardo Coradassi et al. (org.). Ponta Grossa: UEPG/ PROEX, 2020.

40f.; E-book PDF

ISBN: 978-65-86967-04-3 (on line)

DOI: $10.5212 / 86967-04-3$

1. Coronavírus. 2. COVID-19- prevenção. 3. Tratamento suportivo. 4. Tratamentos promissores. I. Coradassi, Carlos Eduardo et al. (Org.). II. T.

CDD: 618.2

Ficha Catalográfica elaborada por Maria Luzia F. B. dos Santos - CRB9/986 


\section{SUMÁRIO}

\section{PREVENÇÃO DA COVID-19}

\section{TRATAMENTO SUPORTIVO}

Identificação de casos suspeitos de sindrome gripal

Medidas para evitar o contágio na Atenção

Primária em Saúde

Estratificação da gravidade da sindrome gripal

Casos leves: manejo terapêutico

sintomático e isolamento domiciliar.

Casos graves: estabilização e

encaminhamento a serviços de

urgência e emergência

Medicamentos para casos sintomáticos ................24

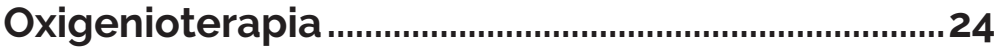

Antibióticos...................................................................25

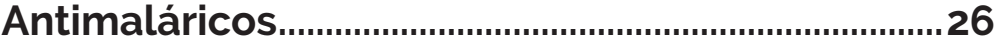

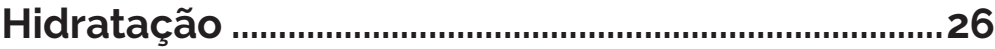

Glicocorticoides ..............................................................26

Dieta

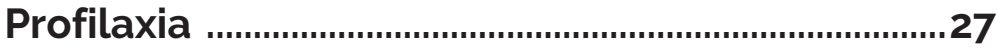

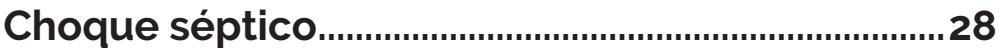

Notificação imediata....................................................31 
Monitoramento clínico .................................................... 32

Medidas de prevenção comunitária e apoio à vigilância ativa....................................................33

Gestantes e puérperas................................................... 34

\section{TRATAMENTOS QUE PARECEM PROMISSORES ATÉ O MOMENTO}

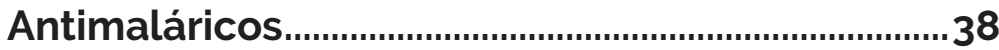

Antibioticoterapia...............................................

Glicocorticoides ...........................................................40

Antihipertensivos.......................................................41

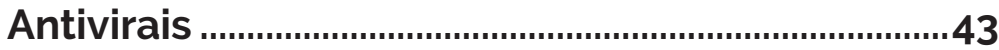

Lopinavir/ritonavir .................................................43

Lopinavir/ritonavir + interferon-beta .....................43

Atazanavir............................................................... 44

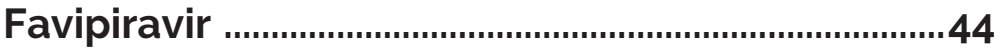

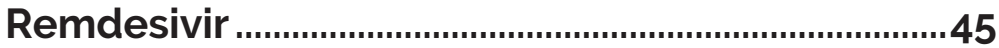

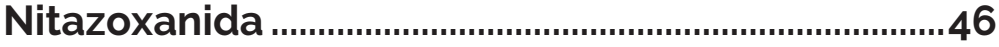




\section{APRESENTAÇÃo}

Ao final do mês de dezembro do ano de 2019, em Wuhan, na China, foi relatado o que se presumia ser o primeiro caso de uma infecção respiratória ainda de etiologia desconhecida. Poucos dias depois, o agente infeccioso foi identificado e, atualmente, é denominado SARS-CoV-2, o novo coronavírus relacionado à síndrome respiratória aguda grave. Em decorrência de sua rápida disseminação, em menos de três meses a COVID-19 - doença causada pelo SARS-CoV-2 - fora declarada pandemia pela Organização Mundial da Saúde (OMS). Devido à recente descoberta da doença, inexistem estudos qualificados acerca de medidas terapêuticas específicas para ela. No entanto, sabe-se e ratifica-se que a prevenção é a melhor forma de tratamento. Neste material, descrevemos o adequado manejo de pacientes em tempos da pandemia de COVID-19. 


\section{PREVENÇÃO DA COVID-19}

A prevenção continua sendo o melhor remédio para o combate ao SARS-CoV-2, o novo coronavírus relacionado à sindrome respiratória aguda grave, visto que ainda não existem vacinas nem fármacos específicos para seu tratamento, conforme esquematizado na Figura 1. Isso acontece por tratar-se de um vírus novo, diferente de todos os demais já conhecidos, com comportamento, transmissão e virulência distintos e não elucidados em sua totalidade pela comunidade científica.

Figura 1: Esquema demonstrando o papel da prevenção para combater o novo coronavirus.

\section{PREVENÇÃO}
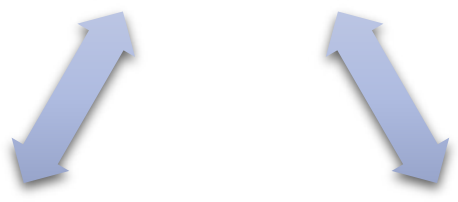

\section{VACINA}

\section{TRATAMENTO ESPECIFICO}

Fonte: Elaborado com base em Ministério da Saúde, 2020. 
No entanto, as medidas de suporte devem ser sempre implementadas, bem como os cuidados com a possivel transmissão do vírus. Assim, o manejo adequado dos casos suspeitos ou confirmados de COVID-19 depende do reconhecimento precoce de sinais de alarme e monitoramento contínuo, como veremos adiante Figura 2.

Figura 2: Esquema mostrando a importância das medidas de suportes no manejo adequado, reconhecimento precoce dos sinais de alarme e monitoramento contínuo dos pacientes acometidos pela COVID-19.

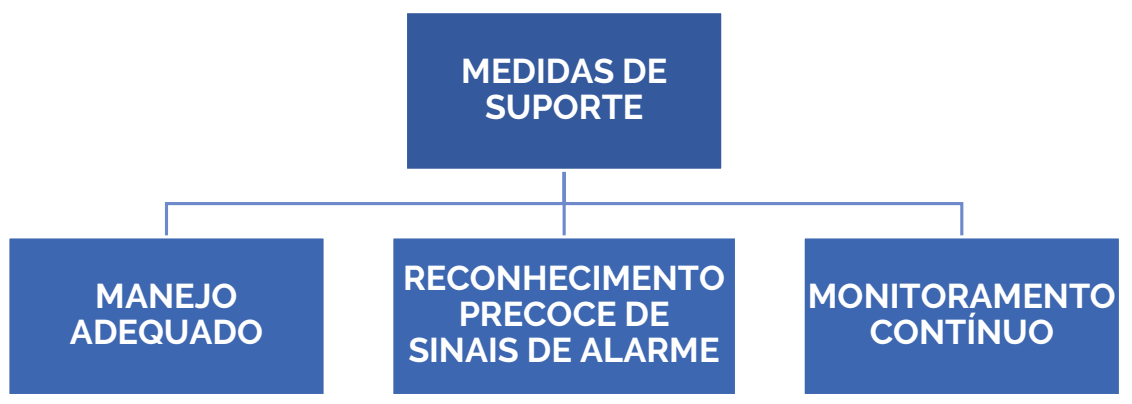

Fonte: Elaborado com base em Ministério da Saúde, 2020. 


\section{TRATAMENTO SUPORTIVO}

O manejo clínico dos pacientes infectados pelo novo coronavírus difere de acordo com a gravidade dos casos. Para os pacientes com sintomas leves, instituem-se apenas medidas de suporte e conforto, bem como orientações para o isolamento domiciliar e monitoramento até a alta do isolamento, normalmente após 14 dias do início dos sintomas. Já para os pacientes com apresentação moderada a grave, realiza-se a estabilização clínica, além do encaminhamento e transporte a centros de referência ou serviço, de urgência e emergência ou hospitalares, conforme a necessidade de cada caso.

A estratificação de risco torna-se uma ferramenta primordial para definir a conduta correta dos pacientes, pois os serviços de atendimento primário devem assumir papel resolutivo frente aos casos leves, principalmente na identificação precoce, além do rápido encaminhamento dos casos graves.

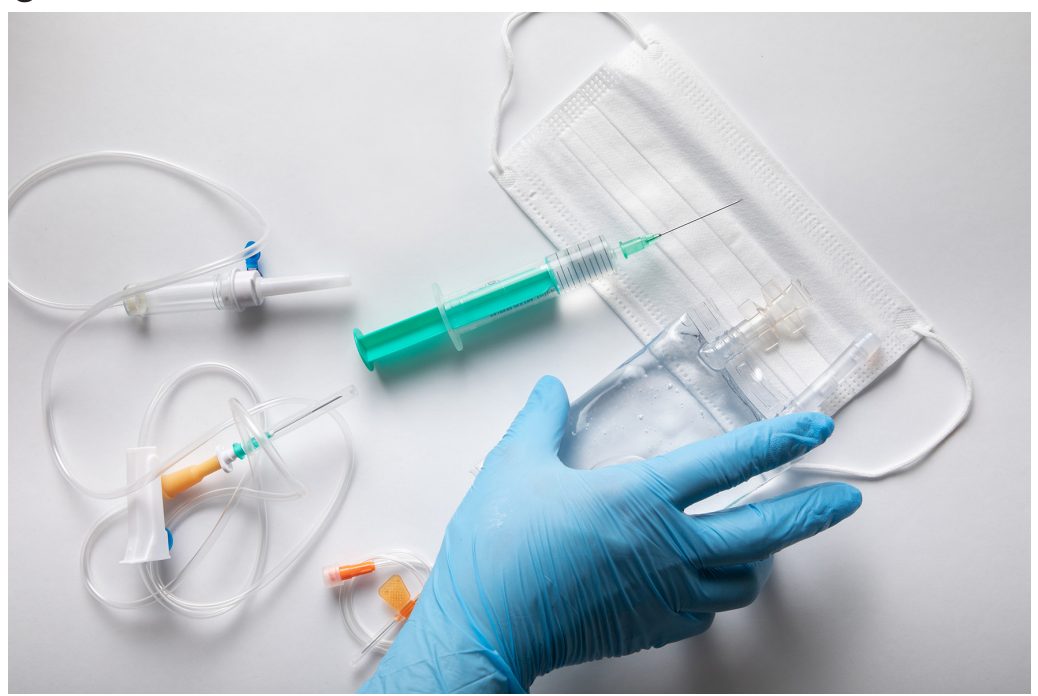


Para esse correto direcionamento e manejo adequado dos pacientes, é de suma importância sistematizar os oito passos preconizados pelo Ministério da Saúde frente a um caso suspeito de infecção pelo SARS-CoV-2, conforme esquematizado na Figura 3.

Figura 3a. Manejo inicial dos pacientes suspeitos de infecção por SARS-CoV-2 nas Unidades Básicas de Saúde

1. IDENTIFICAÇÃO de casos suspeitos de SÍNDROME GRIPAL

2. Medidas para EVITAR O CONTÁGIO na Atenção Primária à Saúde

3. ESTRATIFICAÇÃO da gravidade da Sindrome Gripal

4. CASOS LEVES: manejo terapêutico sintomático e isolamento domiciliar

5. CASOS GRAVES: estabilização e encaminhamento a serviços de urgência e emergência

6. NOTIFICAÇÃO IMEDIATA

7. MONITORAMENTO CLÍNICO

8. MEDIDAS DE PREVENÇÃO

comunitária e apoio à vigilância ativa

Fonte: Elaborado com base em Ministério da Saúde, 2020. 
Figura 3b. Manejo inicial dos pacientes suspeitos de infecção por SARS-CoV-2 nas Unidades Básicas de Saúde

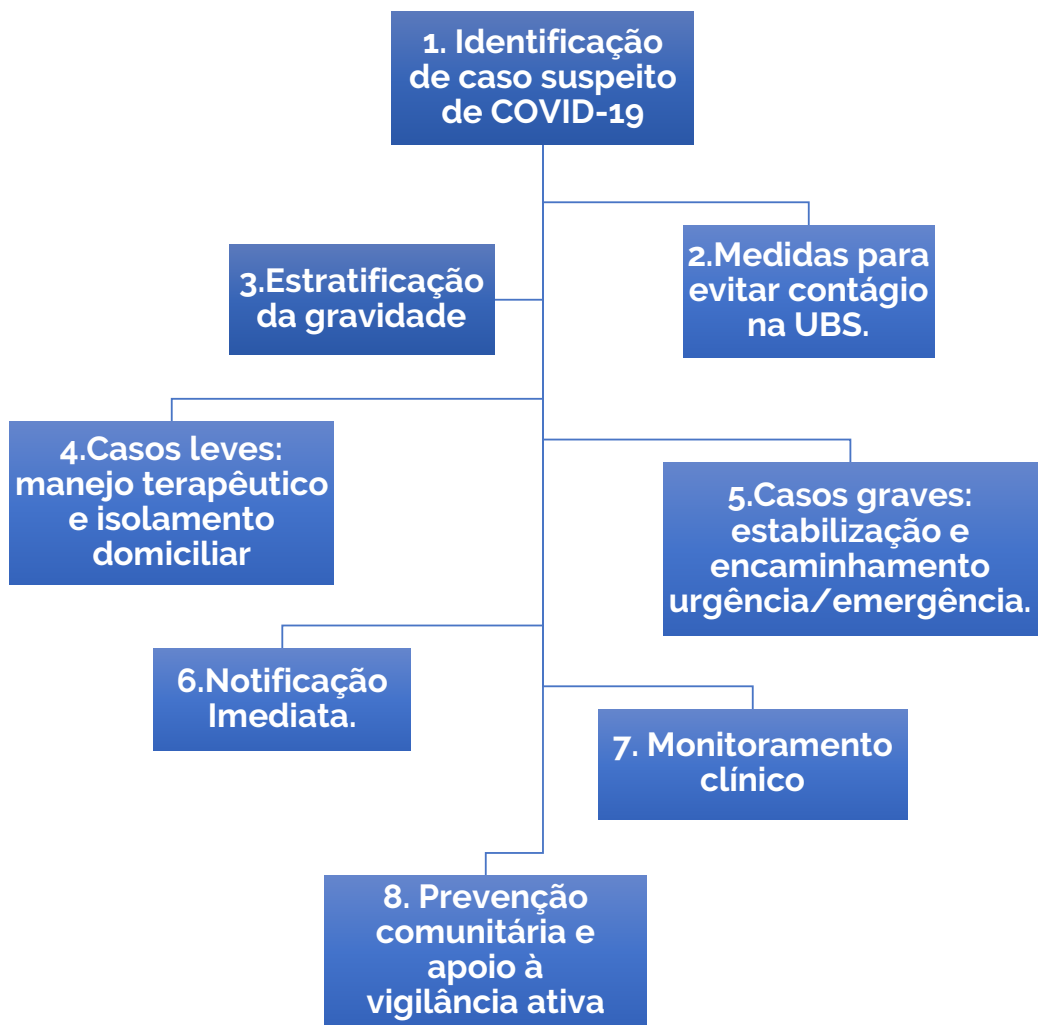

Fonte: Elaborado com base em Ministério da Saúde, 2020.

\section{IDENTIFICAÇÃO DE CASOS SUSPEITOS DE SÍNDROME GRIPAL}

Aqui é fundamental recordar que os principais sinais e sintomas de síndrome gripal são:

- Coriza;

- Indisposição;

- Febre (temperatura axilar $>37,8^{\circ} \mathrm{C}$ ); 
- Inapetência;

- Tosse;

- Espirros.

Essa identificação, quando feita de maneira rápida e eficaz pelos profissionais da Atenção Primária em Saúde (APS), é crucial para o manejo correto dos pacientes, com o objetivo de direcionar o tratamento mais adequado de cada caso.

\section{MEDIDAS PARA EVITAR O CONTÁGIO NA ATENÇÃO PRIMÁRIA EM SAÚDE}

Para impedir a propagação da COVID-19 nos serviços de Atenção Primária em Saúde, faz-se necessário colocar em prática todas as medidas de prevenção coletiva e de proteção individual frente aos casos suspeitos para a infecção pelo novo coronavírus - e de outros vírus respiratórios, os quais continuam circulando concomitantemente ao SARS-CoV-2.

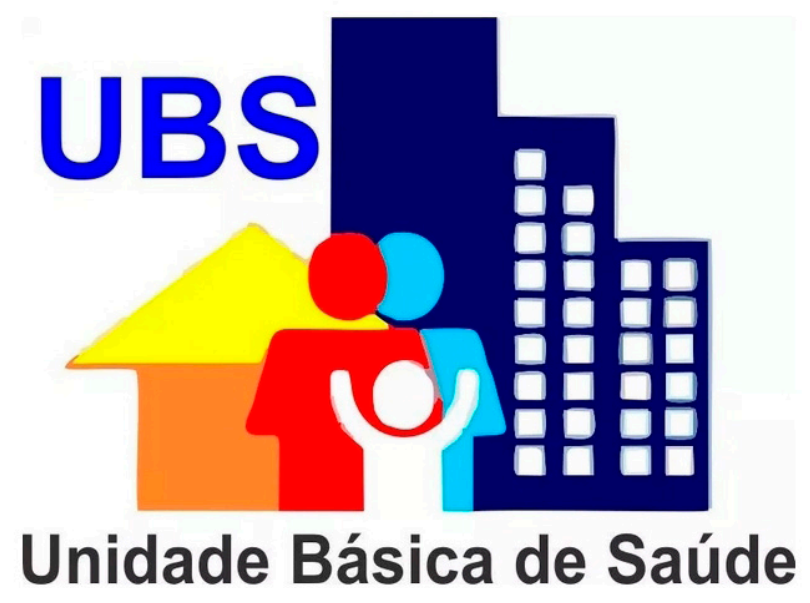

Fonte: Governo Federal. 
Além disso, não se devem poupar orientações aos pacientes e familiares, pois o possivel infectado pelo vírus SARS-CoV-2 também deve adotar medidas de proteção para evitar transmissão à comunidade.

Na Tabela 1 são ressaltadas medidas preventivas para profissionais da saúde e usuários das Unidades Básicas de Saúde (UBS) para reduzir o risco de infecções pelos vírus respiratórios em ambientes de saúde, tais como as UBS.

Tabela 1. Medidas preventivas para minimizar o risco de infecções por vírus respiratórios, como o SARS-CoV-2, nas Unidades Básicas de Saúde (UBS)

\begin{tabular}{c|c} 
PROFISSIONAIS DA SAÚDE & USUÁRIOS DA UBS \\
\hline Contenção respiratória & Máscara cirúrgica \\
\hline Máscara cirúrgica & $\begin{array}{c}\text { Isolamento com precaução de } \\
\text { contato em sala isolada e ventilada }\end{array}$ \\
\hline $\begin{array}{c}\text { Uso de luvas, óculos ou protetor } \\
\text { facial e aventais descartáveis }\end{array}$ & \\
\hline Lavar as mãos com água e sabão & \\
\hline Antissepsia com álcool 70\% INPM & \\
\hline $\begin{array}{c}\text { Desinfecção de objetos e } \\
\text { superficies com hipoclorito de } \\
\text { sódio a o,1\% }\end{array}$ & \\
\hline
\end{tabular}

Fonte: Elaborado com base em Ministério da Saúde, 2020.

\section{ESTRATIFICAÇÃO DA GRAVIDADE DA SÍNDROME GRIPAL}

Após realizada a triagem, os pacientes devem passar por uma consulta médica, a fim de estratificar a gravidade do caso quando for levantada a hipótese diagnóstica de sindrome gripal. 
Dessa maneira, como é possível observar na Tabela 2, a letalidade da COVID-19 eleva-se de modo diretamente proporcional ao aumento da idade. Por isso, os idosos, bem como pessoas com doenças crônicas, gestantes e puérperas devem ter prioridade no atendimento, mesmo porque estão inseridos nos grupos de risco.

Tabela 2. Letalidade provocada pela COVID-19, por faixa etária, na China

\begin{tabular}{c|c}
\hline Idade (anos) & Taxa de letalidade (\%) \\
\hline $10-19$ & 0.2 \\
\hline $20-29$ & 0.2 \\
\hline $30-39$ & 0.2 \\
\hline $40-49$ & 0.4 \\
\hline $50-59$ & 1.3 \\
\hline $60-69$ & 3.6 \\
\hline $70-79$ & 8 \\
\hline$>80$ & 14,8 \\
\hline
\end{tabular}

Fonte: CDC China Weekly, 2020. 
De acordo com as características pessoais e clínicas, histórico de multimorbidades de cada caso sintomático de sindrome gripal, os pacientes podem ser classificados em casos leves ou graves. A depender dessa classificação, o fluxo de encaminhamento e manejo do caso se dá de modo distinto:

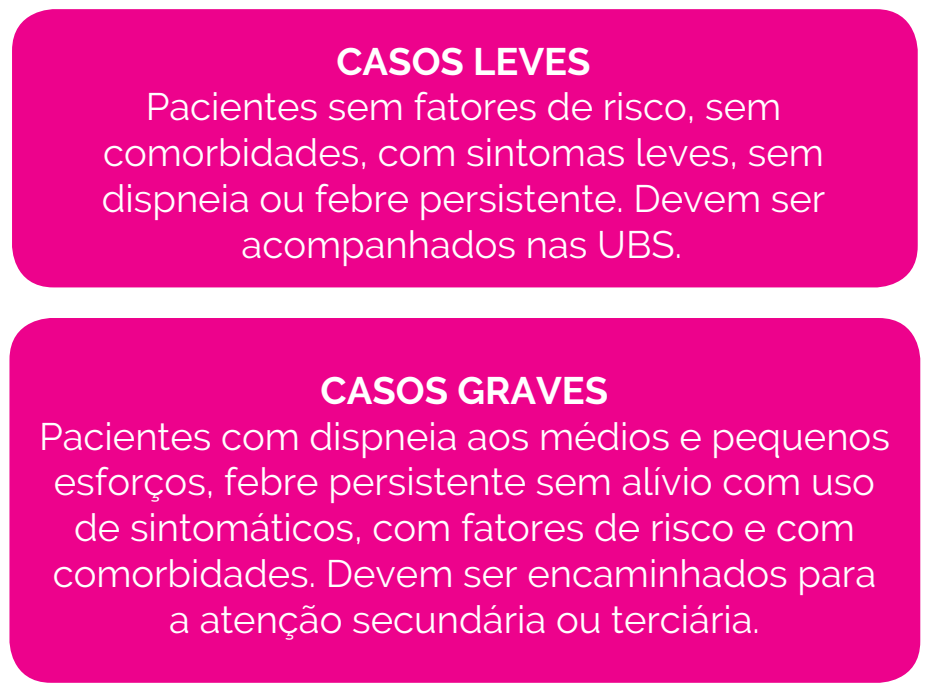

Na Tabela 3, Tabela 4 e Tabela 5 são apresentadas características específicas para a estratificação de risco, sinais e sintomas, como também condições que aumentam o risco de complicações em pessoas que se enquadram no diagnóstico de síndrome gripal. 
Tabela 3. Estratificação da gravidade de casos de sindrome gripal

\begin{tabular}{c|c} 
CASOS LEVES & CASOS GRAVES \\
\hline Atenção Básica & Atenção especializada \\
\hline $\begin{array}{c}\text { Sindrome gripal com sintomas } \\
\text { leves (sem sinais e sintomas de } \\
\text { gravidades) }\end{array}$ & $\begin{array}{c}\text { Sindrome gripal com sinais e } \\
\text { sintomas de gravidade }\end{array}$ \\
\hline $\mathrm{E}$ & OU \\
\hline $\begin{array}{c}\text { Ausência de comorbidades } \\
\text { que indicam avaliação em } \\
\text { centro de referência ou atenção } \\
\text { especializada. }\end{array}$ & $\begin{array}{c}\text { Comorbidades que indicam } \\
\text { avaliação em centro de } \\
\text { referência e atenção } \\
\text { especializada. }\end{array}$ \\
\hline
\end{tabular}

Fonte: Elaborado com base em Ministério da Saúde, 2020.

Tabela 4. Sinais e sintomas que indicam gravidade na sindrome gripal, conforme os sistemas orgânicos

SISTEMA RESPIRATÓRIO

Dispneia ou dificuldade para respirar

\begin{tabular}{c|c} 
respirar & $<60 \mathrm{mmHg})$ \\
\hline $\begin{array}{c}\text { Ronco, retração sub ou intercostal } \\
\text { Cianose central }\end{array}$ & $\begin{array}{c}\text { Perfusão periférica lentificada } \\
\text { SINAIS E SINTOMAS DE ALERTA }\end{array}$ \\
\hline Taquipneia $>30 \mathrm{ipm}$ & $\begin{array}{c}\text { Piora das condições clínicas de } \\
\text { doenças de base }\end{array}$ \\
\hline $\begin{array}{c}\text { Alteração do estado mental: } \\
\text { confusão ou letargia }\end{array}$ \\
\hline $\begin{array}{c}\text { Persistência ou aumento da febre } \\
\text { por mais de } 3 \text { dias, ou retorno } \\
\text { após } 48 \text { horas de periodo afebril. }\end{array}$ \\
\hline
\end{tabular}

\section{SISTEMA CARDIOVASCULAR}

Sinais e sintomas de hipotensão

(PAS $<90 \mathrm{mmHg}$ e/ ou PAD $<60 \mathrm{mmHg}$ )

Fonte: Elaborado com base em Ministério da Saúde, 2020. 
Tabela 5. Comorbidades e fatores de risco para casos graves de síndrome gripal, como a COVID-19

\begin{tabular}{c|c} 
DOENÇAS CARDIACAS & DOENÇAS PULMONARES \\
Fibrose cística & $\begin{array}{c}\text { Transplantados de órgãos } \\
\text { sólidos e medula óssea }\end{array}$ \\
\hline Doença renal crônica & $\begin{array}{c}\text { Displasia broncopulmonar com } \\
\text { complicações e outras doenças } \\
\text { crônicas da prematuridade }\end{array}$ \\
\hline Diabetes mellitus & Gestantes e puérperas \\
\hline Imunossupressão por doenças & $\begin{array}{c}\text { Portadores de sindromes } \\
\text { cromossômicas e estados de } \\
\text { fragilidade imunológica }\end{array}$ \\
\hline
\end{tabular}

Fonte: Elaborado com base em Ministério da Saúde, 2020.

Além da apresentação clínica, as condições domiciliares também devem ser avaliadas antes de se seguir o planejamento de acompanhamento ambulatorial do paciente na Atenção Primária em Saúde. Isso se deve ao fato de que, mesmo em casos de menor gravidade, quando houver menor esclarecimento da populacão exige-se que haja um acompanhante mais próximo para auxiliar no tratamento da síndrome gripal, bem como nas demais comorbidades existentes, além do monitoramento da evolução do quadro e identificação precoce de sinais e sintomas de piora, os quais necessitam de rápida intervenção. 


\section{CASOS LEVES: MANEJO TERAPÊUTICO SINTOMÁTICO E ISOLAMENTO DOMICILIAR}

Os casos leves de COVID-19 devem ser manejados tanto com medidas não farmacológicas, como repouso, hidratação e alimentação adequada, mas também com as estratégias farmacológicas que forem necessárias, com o os analgésicos e os antitérmicos. Ademais, deve-se orientar o isolamento domiciliar por 14 dias a contar da data de início dos sintomas Tabela 6.

Tabela 6. Manejo terapêutico da sindrome gripal na Atenção Primária à Saúde

MEDIDAS FARMACOLÓGICAS

Prescrição de fármacos para controle de sintomas, caso não haja contraindicações.

Antitérmico via oral

Paracetamol $500 \mathrm{mg}$ a cada 4 a 6 horas, se houver dor ou febre Crianças: $10-15 \mathrm{mg} / \mathrm{kg} /$ dose (máximo 5 doses ao dia).

\section{MEDIDAS CLIINICAS}

Isolamento domiciliar por 14 dias

a contar da data de início dos sintomas.
Revisão a cada 24 horas, preferencialmente por telefone,

realizando atendimento

presencial, se necessário, por parte do profissional de saúde da Unidade Básica de Saúde.

Dipirona (solução gotas 500mg/ $\mathrm{ml}$ ou $500 \mathrm{mg} /$ comprimido) em caso de dor ou febre a cada 6 horas.

Crianças: > 3 meses (lactentes $10 \mathrm{mg} / \mathrm{kg} /$ dose e pré-escolar $15 \mathrm{mg} / \mathrm{kg} /$ dose).

Oseltamivir (Tamifluß) é recomendado em casos específicos de suspeita de infecção pelo vírus influenza (em até 48 horas após o início dos sintomas).
Manter repouso, alimentação balanceada e boa oferta de líquidos.

Fonte: Elaborado com base em Ministério da Saúde, 2020. 
Diante da possibilidade de síndrome gripal por outros vírus, como o vírus da influenza, indica-se o uso de oseltamivir em até 48 horas do início dos sinais e sintomas gripais, em especial, diante de alguns fatores de risco para complicações da síndrome gripal, como expostos na Tabela 7.

O uso do oseltamivir nos casos de síndrome gripal deve ser avaliado pelo profissional médico e, quando recomendado por este, pode ser prescrito, de acordo com idade e peso corporal, da seguinte forma:

- 75 mg, de 12 em 12 horas, por 5 dias para adultos;

- Crianças maiores de 1 ano devem ter a dose adequada para o peso;

- $3 \mathrm{mg} / \mathrm{kg}$, de 12 em 12 horas, por 5 dias para crianças até 8 meses de idade;

- $\quad 3.5 \mathrm{mg} / \mathrm{kg}$, de 12 em 12 horas por 5 dias para crianças entre 9 e 11 meses de idade.

Tabela 7. Condições de risco para complicações em casos de sindrome gripal com recomendação para o uso de oseltamivir

\section{SITUAÇÕES QUE RECOMENDAM O USO DE OSELTAMIVIR}

Grávidas em qualquer idade gestacional, puérperas até 2 semanas pós-parto.

Crianças $<5$ anos

População indigena aldeada ou com dificuldade de acesso.

Cardiovasculopatias

Obesidade $\left(\right.$ IMC $\left.>40 \mathrm{~kg} / \mathrm{m}^{2}\right)$

Distúrbios metabólicos

Transtorno neurológico

Acidente Vascular Encefálico

Epilepsia

Lesão medular

Síndrome de Down

Doença neuromuscular 
Tabela 7. Condições de risco para complicações em casos de sindrome gripal com recomendação para o uso de oseltamivir conclusão

\section{SITUAÇÕES QUE RECOMENDAM O USO DE OSELTAMIVIR}

Adultos $>60$ anos

Individuos menores de 19 anos de idade em uso de ácido acetilsalicílico

Pneumopatias

Portadores de tuberculose pulmonar ou extrapulmonar

Nefropatias

Doenças hematológicas (anemia falciforme)

Hepatopatias

Imunossupressão
Medicamentos
Neoplasias
HIV/AIDS

Fonte: Ministério da Saúde, 2017.

Portanto, é fundamental a vigilância ativa e continuada desses pacientes que estão recebendo acompanhamento ambulatorial. É necessária, também, a comunicação constante entre o profissional de saúde e o paciente em cuidados domiciliares até o fim do período de isolamento.

Durante esse cuidado, a revisão dos sintomas e o seguimento da evolução do quadro devem ser realizados por um profissional da Unidade Básica de Saúde, a cada 24 a 48 horas, preferencialmente por telefone, realizando consulta presencial conforme necessidade. 


\section{CASOS GRAVES: ESTABILIZAÇÃO E ENCAMINHAMENTO A SERVIÇOS DE URGÊNCIA E EMERGÊNCIA}

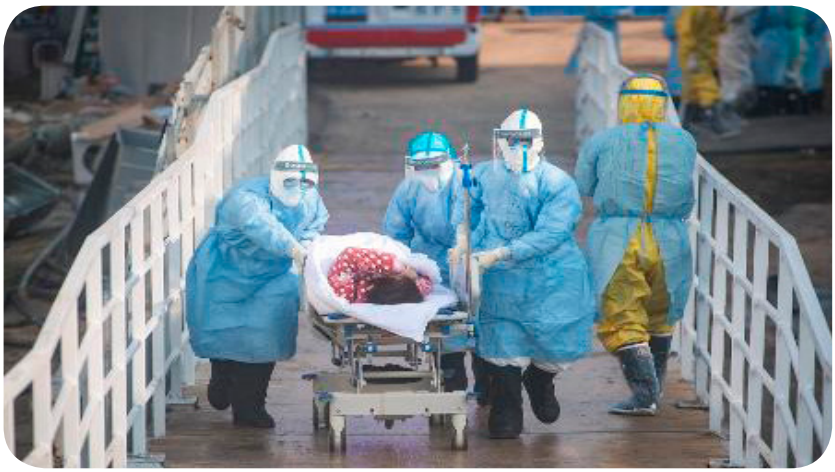

Casos classificados como graves devem ser estabilizados e encaminhados aos serviços de urgência ou hospitalares, de acordo com a organização da Rede de Atenção à Saúde local. Desse modo, o encaminhamento será de responsabilidade da equipe da Atenção Primária onde ocorreu a identificação do caso, sendo essencial também garantir o transporte adequado a esse paciente.

$\bigcirc$ atendimento aos casos graves deve adotar as etapas a seguir:

\section{Identificação de caso suspeito}

2. Estratificação como caso grave

3. Estabilização

4. Encaminhamento

5. Monitoramento 
Durante o atendimento prestado, é fundamental realizar diagnósticos diferenciais pertinentes ao novo coronavírus, bem como seu manejo clínico adequado.

Todos os pacientes que receberem alta durante os primeiros 7 dias do início do quadro devem ser alertados para a possibilidade de piora tardia dos sinais e sintomas, assim como o surgimento de sinais de alerta de complicações, como o aparecimento de febre após período afebril, elevação ou recrudescência de febre ou sinais respiratórios, taquicardia, dor pleuritica, fadiga, dispneia.

Nos casos suspeitos ou confirmados para COVID-19 que não necessitarem de hospitalização e o serviço de saúde optar pelo isolamento domiciliar, o médico poderá solicitar radiografia de tórax, hemograma e provas bioquímicas antes de liberar o paciente para o domicilio, sempre em dependência da avaliação clínica previa.

Esses pacientes sempre devem ser orientados sobre o controle de infecção, prevenção de transmissão para os que tiverem tido contato com eles, além de sinais de alerta para possíveis complicações. Um acesso por meio de comunicação rápida deve ser providenciado para eventuais dúvidas ou esclarecimentos.

Recomenda-se a hospitalização para os pacientes que apresentem fatores de risco para complicações da síndrome gripal, além de um quadro clínico exuberante. É importante salientar que há necessidade de uma avaliação individualizada de cada caso.

Para os pacientes que apresentem dispneia, tosse, sibilo com ou sem dificuldade respiratória, devido ao aumento da secreção das vias respiratórias inferiores, sugere-se o uso de anticolinérgicos, como o brometo de ipratrópio. 
Além disso, nos pacientes com disfunção da cascata de coagulação, para reduzir o risco de tromboembolismo, pode-se utilizar um anticoagulante, como a heparina não fracionada (HNF) ou de baixo peso molecular (HBPM).

\section{Medicamentos para casos sintomáticos}

Sugere-se a administração de medicamentos sintomáticos, como antipiréticos, analgésicos, antitussigenos ou expectorantes e antieméticos, sempre que haja indicação clínica, respeitando o quadro do paciente e as contraindicações. Amparada nas evidências e incertezas sobre a utilização do ibuprofeno e outros antinflamatórios não esteroidais (AINES), a recomendação da Organização Mundial da Saúde (OMS) é utilizar, preferencialmente, paracetamol e dipirona para controle térmico e analgesia, como já exposto anteriormente.

\section{Oxigenioterapia}

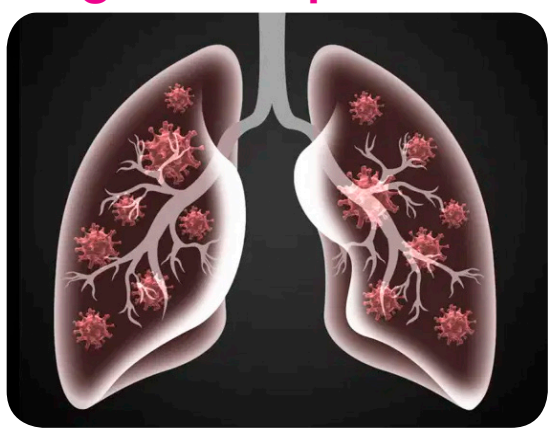

Deve-se proceder com a suplementação de oxigênio nos pacientes com sinais de insuficiência respiratória aguda. A observação dos procedimentos que aumentam o risco de aerossolização dos vírus respiratórios é necessária, tais como: cateter nasal de alto fluxo (CNAF) e ventilação não invasiva (VNI). Alguns sinais de insuficiência respiratória 
estão listados a seguir:

- Esforço respiratório;

- Taquidispneia;

- Tiragem intercostal;

- Uso de musculatura acessória;

- Saturação periférica de oxigênio < 90\%.

A ausência de resposta ou piora clínica diante da oxigenioterapia suplementar requer intervenções mais agressivas, como ventilação não invasiva (VNI).

A submissão dos pacientes à ventilação mecânica (VM) deve ser indicada por meio da intubação orotraqueal (IOT) por médico capacitado para tal procedimento, respeitando as medidas de precaução contra aerossóis, pois assim como a VNI, a IOT também é um procedimento aerossolizador. Deve-se programar o ventilador usando volume-corrente entre 4 e $6 \mathrm{ml} / \mathrm{kg}$ de peso corporal previsto e pressão de platô $<30 \mathrm{~cm} \mathrm{H}_{2} \mathrm{O}$.

Além disso, é importante evitar que o paciente se desconecte do ventilador mecânico, pois isso resultaria em perda da pressão expiratória final positiva (PEEP) e consequente atelectasia por colabamento alveolar.

\section{Antibióticos}

A COVID-19 é uma doença causada pelo SARS-CoV-2, um agente infeccioso viral, portanto, antibióticos não se encontram indicados especificamente para essa doença. Porém, alguns pacientes podem apresentar infecções bacterianas sobrepostas e evoluir com sepse de foco pulmonar. Sendo assim, na vigência de uma possível pneumonia bacteriana isolada ou concomitante, deve-se 
administrar antibióticos com cobertura para microrganismos patogênicos pulmonares, como ceftriaxona e azitromicina.

\section{Antimaláricos}

A hidroxicloroquina e a cloroquina são antimaláricos, sendo que o Ministério da Saúde autoriza o seu uso em casos de pacientes hospitalizados em situação grave ou crítica da COVID-19. Enfatiza-se que nenhum destes medicamentos deve ser usado nas formas leves ou moderadas, nem como profilaxia da infecção viral, posto que pode resultar em efeitos colaterais graves. Além disso, é válido ressaltar que esses fármacos não têm eficácia comprovada para combater a infecção pelo SARS-CoV-2.

\section{Hidratação}

A hidratação venosa deve ser realizada, somente, mediante indicação. Não se encontra recomendada sua administração profilática em pacientes hospitalizados com sindrome gripal, principalmente em decorrência de seus possiveis efeitos colaterais, como congestão pulmonar, hipervolemia e sobrecarga renal.

\section{Glicocorticoides}

Encontra-se prescrita a administração de glicocorticoides sistêmicos, como a prednisona ou dexametasona, para o tratamento de pneumonia viral ou síndrome respiratória aguda grave, como as causadas pelo novo coronavírus. 0 uso desses medicamentos só está recomendado mediante indicação, como exacerbação de doença pulmonar obstrutiva crônica (DPOC) ou crise asmática. 


\section{Dieta}

É de suma importância garantir a adequada suplementação energética com estímulo à ingestão de dieta balanceada ou adaptada às necessidades do paciente, levando-se em conta a existência de comorbidades.

\section{Profilaxia}

Em pacientes hospitalizados, é fundamental obedecer ao cuidado multidisciplinar. Nesse sentido, algumas profilaxias devem acontecer durante a internação dos pacientes e isso não é diferente para os casos suspeitos ou confirmados da infecção pelo novo coronavírus.

Deve haver o manejo adequado do paciente, de forma a evitar úlceras por pressão, seguindo os protocolos específicos de profilaxia. Consulte o protocolo disponibilizado pela Agência Nacional de Vigilância Sanitária para mais informações acerca da profilaxia contra as úlceras de pressão.

Para a profilaxia contra as úlceras de estresse, indicamse inibidores de bomba de prótons (IBP), como o omeprazol, ou anti-histamínicos $\left(\mathrm{H}_{2}\right)$, como a ranitidina. Porém, deve-se observar a função renal para administrar esse fármaco. As úlceras de estresse têm maior prevalência nos pacientes com sangramento do trato gastrointestinal, ventilação mecânica por mais de 48 horas, disfunção da coagulação, hemodiálise, doença hepática, entre outras situações.

É fundamental que haja monitoramento dos pacientes com sindrome respiratória aguda grave, em especial quanto aos sinais de complicações clínicas, como a insuficiência respiratória aguda, sepse, choque séptico, miocardite fulminante e choque cardiogênico. 


\section{Choque séptico}

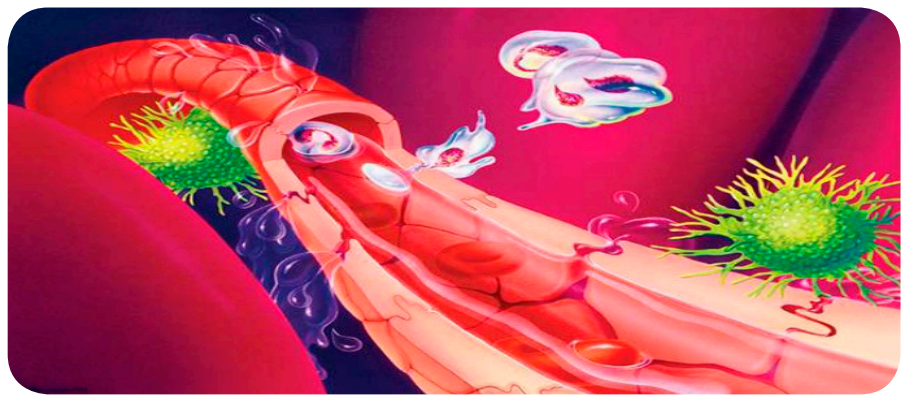

O reconhecimento precoce do choque séptico em adultos e crianças é necessário. O choque séptico ocorre diante de um foco infeccioso e necessidade do uso de vasopressores para manter a PAM (pressão arterial média) $\geq 65 \mathrm{mmHg}$.

É possivel reconhecer o choque séptico em crianças com hipotensão ou de dois a três dos seguintes critérios:

- Estado mental alterado;

- Taquicardia ou bradicardia (frequência cardíaca de 160 bpm em bebês e 150 bpm em crianças);

- Enchimento capilar prolongado (> 2 segundos);

- Taquidispneia;

- Livedo reticular;

- Erupção petequial ou purpúrica;

- Aumento de lactato;

- Oligúria;

- Hipertermia ou hipotermia.

Na ressuscitação do choque séptico em adultos, administrar pelo menos $30 \mathrm{ml} / \mathrm{kg}$ de cristalóide isotônico em adultos nas primeiras 3 horas. Já em crianças em locais com bons recursos, administrar $20 \mathrm{ml} / \mathrm{kg}$ em bolus rápido e até $40-60 \mathrm{ml} / \mathrm{kg}$ na primeira hora. Não usar soluções hipotônicas ou baseadas em amidos para ressuscitação. 
Administrar vasopressores quando o choque persistir durante ou após a ressuscitação hídrica. Se os cateteres venosos centrais não estiverem disponiveis, os vasopressores podem ser administrados por meio de um IV periférico, mas usar uma veia grande e monitorar de perto os sinais de extravasamento e necrose tecidual local. Se ocorrer extravasamento, pare a infusão. Os vasopressores também podem ser administrados utilizando-se de agulhas intraósseas.

Considerar administrar hidrocortisona intravenosa (até 200 mg/dia) ou prednisolona (até 75 mg/dia) em pacientes com choque persistente que necessitem de doses crescentes de vasopressores.

A Tabela 8 sintetiza as informações a respeito dos cuidados terapêuticos hospitalares em pacientes suspeitos ou confirmados da infecção pelo novo coronavírus.

\section{ATÉ QUANDO MANTER O ISOLAMENTO DOS PACIENTES INTERNADOS?}

Realizar acompanhamento diário dos pacientes

e manter isolamento até duas amostras de

PT-PCR consecutivas negativas colhidas em intervalo de pelo menos 24 horas.

\section{RT-PCR}

É o exame que realiza o diagnóstico etiológico do novo coronavírus.

É a reação em cadeia da polimerase em tempo real.

Porém, atualmente, é escassa a disponibilidade desses testes, tanto em território nacional quanto internacional. 
Tabela 8. Resumo dos cuidados terapêuticos hospitalares nos pacientes com suspeita ou confirmação da COVID-19

\section{RESUMO DE CUIDADOS TERAPÊUTICOS}

Precauções de contato, gotículas e aerossóis.

Suporte ventilatório .

Reconhecer rapidamente evolução para insuficiência respiratória e tratar adequadamente.

Não utilizar corticosteroides a menos que haja indicação formal.

Não hidratar demasiadamente o paciente.

Dieta conforme comorbidades e necessidade.

Recomenda-se prescrever empiricamente fosfato de oseltamivir (inibidor da neuraminidase) até resultado de PCR para influenza em casos suspeitos ou com risco aumentado de complicações.

Manter demais medicações do paciente e controlar comorbidades.

Profilaxia de trombose venosa profunda e tromboembolismo pulmonar.

Identificação e manejo rápido em caso de choque séptico.

Nos quadros graves (sepse) e nas infecções associadas a agentes bacterianos, utilizar antimicrobianos.

Profilaxia úlcera de estresse.

Sintomáticos, se necessário (preferencialmente dipirona e paracetamol).

Profilaxia para úlcera de pressão.

Uso de hidroxicloroquina ou cloroquina em casos graves e críticos da COVID-19.

Fonte: Protocolo do Manejo Clínico da COVID-19 na Atenção Especializada, 2020. 


\section{NOTIFICAÇÃO IMEDIATA}

Figura 4. Ficha de Registro Individual para casos de Sindrome Respiratória Aguda Grave (SRAG)

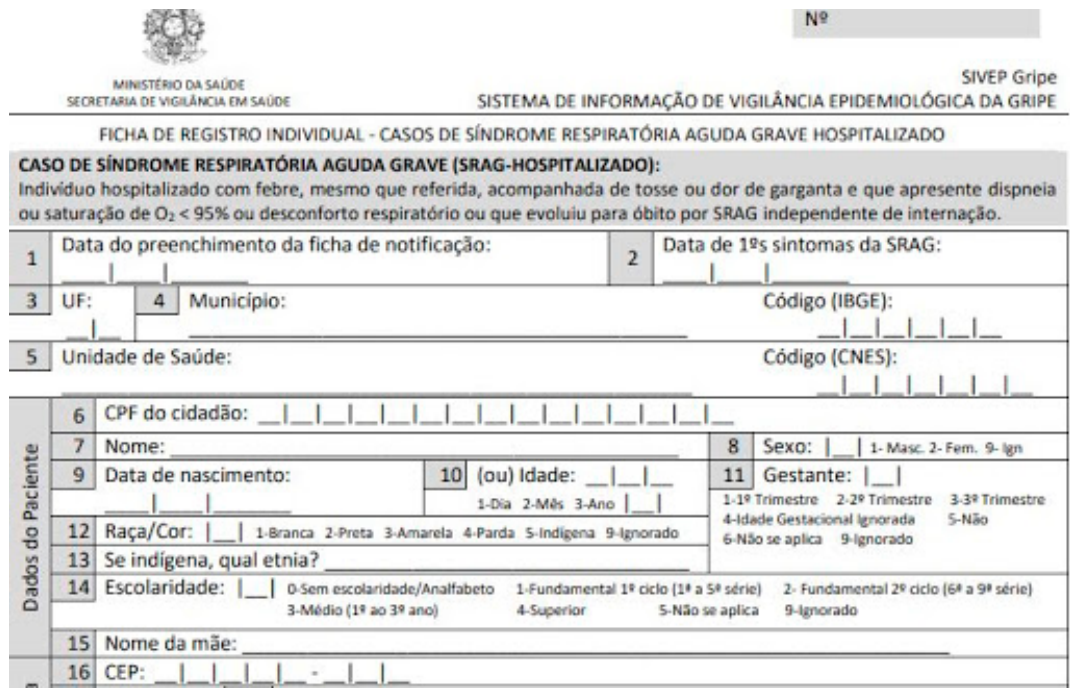

Fonte: Ministério da Saúde, 2020.

É obrigatória a notificação imediata de caso de síndrome gripal, ou seja, em até 24 horas da suspeita ou confirmação do caso, por meio da plataforma do e-SUS, no endereço eletrônico <https://notifica.saude.gov.br>, com o CID-10 mais fidedigno, conforme descrito na Tabela 9.

Além da notificação, as informações de todos pacientes com síndrome gripal devem ser registradas no prontuário, para possibilitar a longitudinalidade e a coordenação do cuidado, assim como realizar eventual investigação epidemiológica e posterior formulação de políticas e estratégias de saúde pública. 
Tabela 9. Códigos da Classificação Internacional de Doenças e Problemas Relacionados à Saúde, 10 revisão (CID-10) para o correto preenchimento da ficha de notificação obrigatória.

\section{NOTIFICAÇÃO DOS CASOS SUSPEITOS OU CONFIRMADOS DA} COVID-19

J11 - Sindrome Gripal Inespecífica.

U07.1 - Infecção pelo novo Coronavírus (COVID-19).

B34.2 - Infecção por Coronavirus de localização não especificada.

CIAP-2 R74: Infecção Aguda de Aparelho Respiratório Superior.

Fonte: Elaborado com base em Ministério da Saúde, 2020.

\section{MONITORAMENTO CLÍNICO}

Enfatiza-se que os pacientes com sindrome gripal, em acompanhamento ambulatorial na Atenção Primária à Saúde, devem permanecer em isolamento domiciliar por 14 dias, a contar da data de início dos sinais e sintomas. Dessa forma, o monitoramento deve ser repetido em intervalos de 24 a 48 horas, preferencialmente por telefone, e realizado o atendimento presencial conforme necessidade, no domicilio do paciente, se possivel. É importante lembrar que todos os membros da casa devem ser considerados contatos próximos e por isso devem ser afastados por 14 dias e acompanhados pelos profissionais de saúde da Unidade Básica de Saúde.

A Tabela 10 exemplifica os cuidados a serem tomados durante o monitoramento dos pacientes com sindrome gripal - suspeito ou confirmado de COVID-19. 
Tabela 10. Monitoramento dos pacientes suspeitos ou confirmados da COVID-19.

\section{NORMATIVA DE ACOMPANHAMENTO DO PACIENTE EM ISOLAMENTO DOMICILIAR VIA TELEFONE}

Acompanhamento deve ser repetido em intervalos de 24 a 48 horas, até 14 dias após o início dos sintomas, preferencialmente por telefone,

realizando consulta presencial se necessário.

1. Anotar em prontuário o número de contato do paciente e de um acompanhante.

2. Ligação deve ser realizada por profissional de saúde para acompanhamento da evolução clínica.

3. Não há necessidade de gravar a conversa.

4. Anotar informações sobre a conversa telefônica no prontuário

sobre o quadro clínico autorreferido pelo paciente, autoavaliação da necessidade de ir algum profissional até a residência ou consulta presencial na UBS.

Fonte: Ministério da Saúde, 2020.

É de suma importância o treinamento de profissionais de saúde para o reconhecimento de sinais e sintomas de síndrome gripal, bem como a busca ativa de novos casos suspeitos dentro da respectiva área de abrangência.

\section{MEDIDAS DE PREVENÇÃO COMUNITÁRIA E APOIO À VIGILÂNCIA ATIVA}

Na Tabela 11 estão resumidas as principais medidas de prevenção contra síndromes gripais, incluindo a COVID-19, a doença causada pelo novo coronavírus. 
Tabela 11. Síntese das principais medidas de prevenção comunitária contra infecções transmissíveis pelas vias aéreas.

\section{PREVENÇÃO COMUNITÁRIA}

Lavar frequentemente as mãos com água e sabão ou álcool em gel a 70\% INPM.

Utilizar lenço descartável para higiene nasal.

Cobrir nariz e boca quando espirrar ou tossir.

Evitar tocar mucosas de olhos, nariz e boca.

Higienizar as mãos após tossir ou espirrar.

Não compartilhar objetos de uso pessoal como talheres, copos, pratos.

Evitar contato com pessoas que apresentem sinais ou sintomas da doença ou contatos próximos de casos prováveis ou confirmados, lembrando que pessoas assintomáticas também transmitem o SARS-

CoV-2.

Fonte: Ministério da Saúde, 2020.

\section{Gestantes e puérperas}

Atualmente, as evidências científicas posicionam as gestantes e puérperas como pertencentes ao grupo de risco para a infecção pelo SARS-CoV-2. Desse modo, devem-se adotar medidas de proteção para a mãe e a criança, isto é, o binômio materno-fetal. Esse grupo tem maior potencial de risco para desenvolvimento de síndrome respiratória aguda grave por síndrome gripal decorrente do novo coronavírus e, também, do vírus influenza. Dessa forma, é importante seguir as recomendações propostas com base nas evidências científicas atuais (Tabela 12).

As gestantes com suspeita ou confirmação da infecção pelo novo coronavírus devem ser tratadas com terapias de suporte, como exposto anteriormente, levando em consideração as adaptações fisiológicas da gravidez. 
O uso de agentes terapêuticos ainda em estudo deve ser guiado por uma análise de risco-benefício individual, baseada no benefício potencial para a mãe e a segurança do feto, com consulta a um especialista em obstetrícia e comitê de ética em pesquisa com seres humanos.

As consultas a especialistas em obstetrícia, neonatal e terapia intensiva (dependendo da condição da mãe) são essenciais para a decisão sobre o parto de emergência e a interrupção da gravidez. Essas consultas devem ser norteadas por fatores como idade gestacional, condição materna e estabilidade fetal; lembrando que a COVID-19, isoladamente, não leva à indicação de parto cesáreo.

De acordo com as orientações da Federação Brasileira das Associações de Ginecologia e Obstetrícia (Febrasgo), diante da possibilidade de interrupção prematura da gestação, o uso de corticoide antenatal deverá ser avaliado individualmente, para promover a maturidade pulmonar fetal.

É recomendada a manutenção do aleitamento materno caso haja infecção da mãe pela COVID-19, levando-se em conta o benefício do aleitamento e a ausência, até o momento, de evidências de transmissão do vírus por essa via, desde que sejam seguidas as normas de precauções já estudadas, como higienização correta das mãos, uso de máscara enquanto estiver amamentando, cuidado com o recém-nascido, entre outras medidas já expostas. 
Tabela 12. Recomendações para gestantes e puérperas com síndrome gripal e risco para desenvolver a COVID-19.

\section{GESTANTES}

A queixa de dispneia deve ser valorizada, mesmo podendo representar manifestação

fisiológica da gravidez.

Pacientes com sinais de agravamento, incluindo SpO2<95\%, considerar o início imediato de oxigenioterapia, monitoramento contínuo e encaminhamento a hospital, se necessário.

\section{PUÉRPERAS}

Manter a amamentação, utilizando máscaras durante todo o cuidado ao recém-nascido.

Mesmo vacinadas, devem ser tratadas com antiviral oseltamivir (Tamiflu $\AA$ ), na dose habitual para adultos, independente de sinais de agravamento, visando redução de morbidade materna na vigência de sindrome gripal.

Não se deve protelar a realização de exame radiológico em qualquer período gestacional se houver suspeita de pneumonia.

Em caso de febre usar antitérmico, visto que hipertermia materna causa lesões fetais. Melhor opção é o paracetamol.

Manter distância mínima a entre a mãe e o berço de 1 metro. Preferencialmente colocar mãe e filho para dormir em quartos separados.
Realizar etiqueta respiratória e higienizar as mãos após tocar nariz, boca e sempre antes do cuidado com o recém-nascido.

Fonte: Ministério da Saúde, 2020. 


\section{TRATAMENTOS QUE PARECEM PROMISSORES ATÉ O MOMENTO}

Atualmente, não há evidências suficientes que possibilitem a indicação de uma terapia farmacológica específica para a COVID-19. Vários estudos foram e estão sendo realizados desde o início da pandemia no final de 2019, em busca de alternativas terapêuticas para o tratamento da infecção pelo SARS-CoV-2.

Nessa perspectiva se encontram os estudos que analisam os efeitos das classes de fármacos listadas a seguir para o tratamento da infecção do trato respiratório causada pelo novo coronavírus, como é possível observar na Figura 5 :

- Antivirais;

- Antirretrovirais;

- Glicocorticoides;

- Antimaláricos;

- Anti-hipertensivos;

- Bacteriostáticos;

- Bactericidas.

No entanto, a maioria dessas terapias não possui registro em bula para uso na infecção pelo vírus, além de se basearem apenas em conceitos teóricos para este fim, levando-se em conta o tempo desde a descoberta do novo coronavírus. 
Figura 5. Esquema evidenciando as principais classes farmacológicas estudadas para o tratamento especifico da COVID-19, salientando-se que, até o momento, apenas a hidroxicloroquina (antimalárico) e o remdesivir (antiviral) encontram-se liberados por autoridades em saúde para o manejo da infecção pelo SARS-CoV-2 em situações específicas

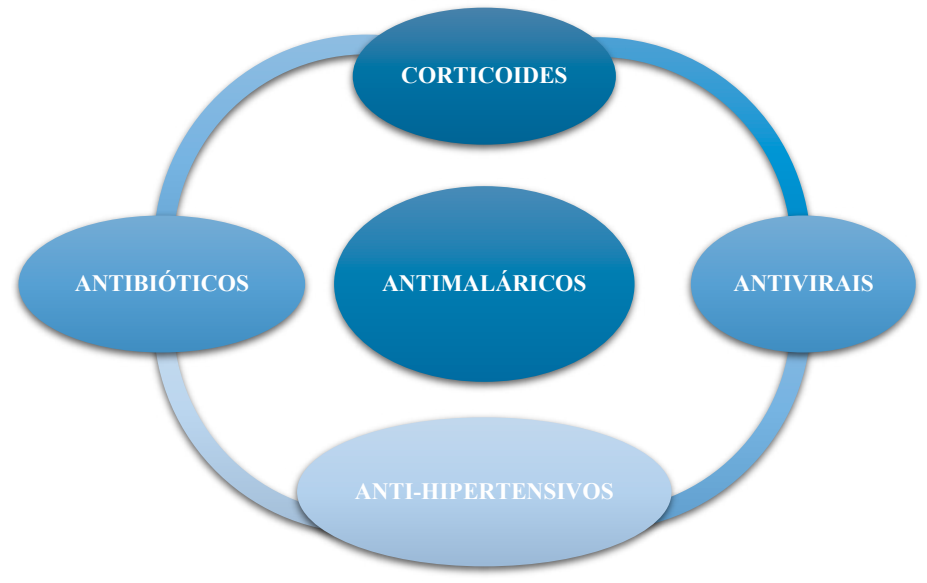

\section{ANTIMALÁRICOS}

De acordo com os estudos acerca do uso dos antimaláricos para o tratamento da COVID-19, a cloroquina e a hidroxicloroquina parecem bloquear a entrada do SARSCoV-2 nas células do hospedeiro, por meio da inibição da glicosilação dos receptores das células infectadas, do processamento proteolítico e da acidificação endossômica. Ademais, esses fármacos demonstram considerável efeito imunomodulador pela da interferência na produção de citocinas.

Segundo a Nota Informativa n. 6/2020 - DAF/SCTIE/ MS (Ministério da Saúde, 2020), baseado nas pesquisas sobre o medicamento e sua disponibilidade no âmbito do Sistema Único de Saúde (SUS), orienta a possibilidade de uso da cloroquina e hidroxicloroquina em casos específicos 
e a critério médico: em casos confirmados como terapia adjuvante no tratamento de formas graves, em pacientes hospitalizados e em estado grave ou crítico, sem que outras medidas de suporte sejam preteridas e respeitando as contraindicações do fármaco, bem como as potenciais reações adversas.

As orientações sobre o uso da cloroquina e hidroxicloroquina estão descritas no quadro a seguir, retirado da mesma nota informativa (Tabela 13). Veja a integra das orientações da Nota Técnica no endereço: <https:// phila.nescon.medicina.ufmg.br/source/covid_19_caso1/ introducao/documentos/nota_informativa06_2020_DAF_ SCTIE.pdf>.

Tabela 13. Indicações e recomendações do uso de antimaláricos na COVID-19

\begin{tabular}{|c|c|c|}
\hline Situação clínica & Recomendação & Considerações \\
\hline $\begin{array}{c}\text { Pacientes } \\
\text { hospitalizados } \\
\text { com formas } \\
\text { graves (dispneia, } \\
\text { taquipneia, } \\
\text { saturação de } \\
\text { oxigênio < 93\%, } \\
\text { infiltrado pulmonar } \\
>50 \% \text { em 24/48 } \\
\text { horas, PaO / } \\
\text { FiO < 300) ou } \\
\text { críticas (choque } \\
\text { séptico, falência } \\
\text { pulmonar com ou } \\
\text { sem falência de } \\
\text { múltiplos órgãos) } \\
\text { da COVID-19. }\end{array}$ & $\begin{array}{c}\text { CLOROQUINA } \\
900 \text { mg de dose de } \\
\text { ataque no } 1^{\circ} \text { dia ( } 3 \\
\text { comprimidos de } 150 \\
\text { mg de } 12 \text { em } 12 \text { horas) } \\
+450 \text { mg/dia no } 2^{\circ}, 3^{\circ} \text {, } \\
4^{\circ} \text { e } 5^{\circ} \text { dias. } \\
\text { HIDROXICLOROQUINA } \\
\text { 800 mg de dose de } \\
\text { ataque no } 1^{\circ} \text { dia ( } 1 \\
\text { comprimido de } 400 \\
\text { mg de } 12 \text { em } 12 \text { horas) } \\
+400 \text { mg/dia no } 2^{\circ}, 3^{\circ} \\
4^{\circ} \text { e } 5^{\circ} \text { dias. }\end{array}$ & $\begin{array}{c}\text { Ajustar dose da } \\
\text { cloroquina para 7.5mg/ } \\
\text { kg se pacientes tiverem } \\
\text { < } 60 \mathrm{~kg} . \\
\text { Verificar o } \\
\text { eletrocardiograma } \\
\text { antes do início } \\
\text { da terapia com } \\
\text { antimaláricos, } \\
\text { pois pode haver } \\
\text { prolongamento } \\
\text { do intervalo QT e } \\
\text { predispor a arritmias } \\
\text { em pacientes } \\
\text { suscetiveis. Manter } \\
\text { monitoramento nos } \\
\text { dias subsequentes. }\end{array}$ \\
\hline
\end{tabular}

Fonte: Ministério da Saúde, 2020. 


\section{ANTIBIOTICOTERAPIA}

Recomenda-se evitar o uso inadequado dos fármacos pertencentes à classe dos antibióticos, especialmente a combinação de antibacterianos de amplo espectro, devido ao potencial desenvolvimento de resistência bacteriana.

Todavia, existem pesquisas em andamento que associam a hidroxicloroquina com a azitromicina (antimicrobiano pertencente à classe dos macrolideos) para avaliar seu efeito no controle da pneumonia causada pelo SARS-CoV-2. No entanto, essa combinação não está em vigor no Brasil.

A indicação da antibioticoterapia, como já foi mencionado, restringe-se à suspeição de infecção bacteriana sobrejacente com ou sem sepse de foco pulmonar.

\section{GLICOCORTICOIDES}

O uso de glicocorticoides na infecção pelo SARSCoV-2 ainda não se encontra recomendado. Alguns estudos sugerem benefícios em subpopulações específicas, enquanto outros sugerem pior prognóstico, além de aumento da carga viral e do tempo de internação.

Assim, a Organização Mundial da Saúde (OMS) e o Centro de Controle e Prevenção de Doenças (CDC) dos Estados Unidos da América recomendam que os glicocorticoides não sejam utilizados no tratamento da síndrome respiratória aguda grave da COVID-19, a menos que haja outra indicação formal para a sua administração, como em episódios de exacerbação de asma, doença pulmonar obstrutiva crônica (DPOC) ou em casos de choque séptico refratário, como já havia sido dito. 
Sabe-se que essa classe farmacológica contém medicamentos derivados do hormônio cortisol e, por isso, apresenta vários mecanismos de ação, tais como:

- Ação anti-inflamatória a partir da inibição da liberação das citocinas pró-inflamatórias na cadeia inflamatória;

- Inibição da ação da fosfolipase $A_{2}$ que é liberada na lesão tissular para quebra do ácido araquidônico, com inibição da formação dos leucotrienos (substâncias que causam vaso ou broncoconstrição, aderência dos neutrófilos ao local inflamatório, aumento da permeabilidade vascular);

- Dificultam a deposição de fibrina e a proliferação de fibroblastos para o processo de cicatrização, portanto, retardando os processos de cicatrização (última etapa do processo inflamatório);

- Efeitos imunodepressores devido à diminuição da liberação da histamina pelos mastócitos e basófilos, supressão dos niveis de bradicinina, diminuição da proliferação linfócitos, principalmente linfócitos $\mathrm{T}$, prejudicando o reconhecimento dos antígenos.

\section{ANTI-HIPERTENSIVOS}

Muitos estudos sugerem que o vírus SARS-CoV-2, devido ao seu mecanismo de ligação ao receptor da ECA-2 (enzima conversora de angiotensina II), pode desencadear maior risco de agravamento em pacientes que fazem uso de IECA (inibidores da enzima conversora de angiotensina) e BRA (bloqueadores dos receptores de angiotensina), e outros estudos endossam o papel benéfico dos fármacos na patogenia do novo coronavírus, levando à diminuição da concentração de angiotensina $\|$ e redução da permeabilidade pulmonar, sendo assim até mesmo uma forma de tratamento, de acordo com as Diretrizes para Diagnóstico e Tratamento da COVID-19. 
Portanto, como não há evidências concretas até o momento, não é recomendado o uso de IECA (como captopril ou maleato de enalapril) e BRA (como a losartana potássica) como opções terapêuticas para a COVID-19. Do mesmo modo que pacientes hipertensos, com doenças cardiovasculares ou diabéticos que já fazem uso desses fármacos como terapia devem manter seus tratamentos, sem a necessidade de suspensão.

O mecanismo de ação dos fármacos citados está esquematizado na Figura 6.

Figura 6. Efeitos farmacológicos dos anti-hipertensivos IECA e BRA.

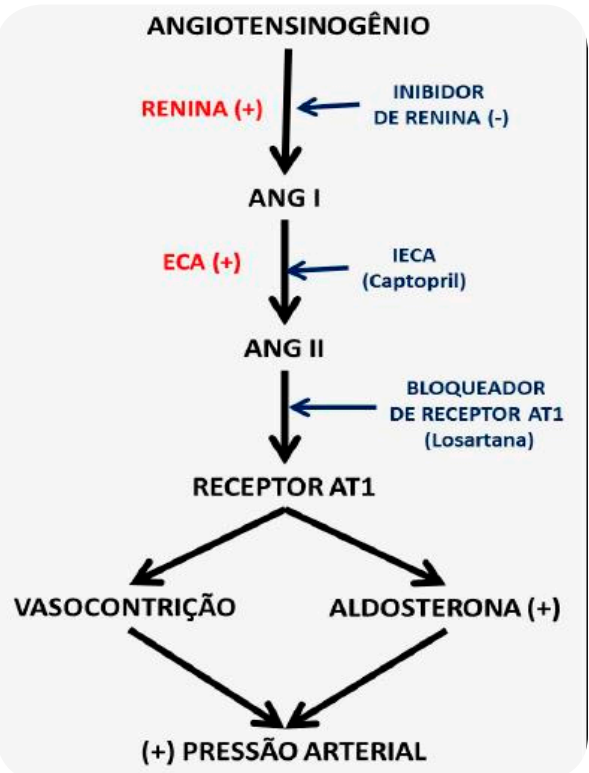

Fonte: Revista Cientifica da Faculdade de Educação e Meio Ambiente, 2017. 


\section{ANTIVIRAIS}

Existem estudos com resultados publicados até o momento avaliando o uso dos seguintes fármacos: lopinavir/ ritonavir (Kaletra $\left.{ }^{\circledR}\right)$, atazanavir, favipiravir, remdesivir e umifenovir.

Os antivirais testados até o momento são:

\section{Lopinavir/ritonavir}

O lopinavir e ritonavir são fármacos já utilizados para o tratamento da infecção pelo vírus da imunodeficiência humana (HIV), pertencendo à classe dos inibidores de protease.

Porém, até o momento, os estudos são contrários à administração desses fármacos para o manejo da COVID-19.

\section{Lopinavir/ritonavir + interferon-beta}

O lopinavir e o ritonavir são os mesmos fármacos citados no item anterior, contudo, a segunda molécula (interferon-beta) está envolvida nos processos inflamatórios do corpo, possuindo efeito citopático e também atuando na inibição da replicação viral. Ela também se mostrou eficiente em combater o vírus MERS-Cov (o segundo coronavírus relacionado à síndrome respiratória aguda grave do Oriente Médio) em outros mamíferos.

\section{Atazanavir}

O antirretroviral atazanavir também pertence à classe dos inibidores de protease e já é utilizado no tratamento de pessoas portadoras do vírus HIV. O fármaco demonstrou redução de até cem vezes na velocidade de replicação do vírus SARS-CoV-2, segundo pesquisas feitas na Fiocruz 
no Brasil. Contudo, ainda o medicamento não se encontra liberado para o manejo da COVID-19.

\section{Favipiravir}

O favipiravir é um antiviral que pode ser usado contra o vírus influenza e seu mecanismo de ação visa impedir a cópia do material genético pelo vírus, interferindo dessa forma na sua replicação. Seu uso como terapia para os pacientes infectados pelo SARS-CoV-2 está sendo realizado por meio de pesquisas no Japão. Possui como efeitos colaterais abortamento espontâneo e malformação fetal, logo é contraindicado em gestantes.

\section{Remdesivir}

O remdesivir é um medicamento antiviral análogo de nucleotídeo patenteado pela indústria biofarmacêutica Gilead Sciences. Inicialmente, o fármaco foi desenvolvido para combater o vírus ebola, porém, não evidenciou resultados satisfatórios. Desde o início da pandemia da COVID-19, o remdesivir tem se mostrado uma das drogas mais promissoras para o combate da infecção pelo SARSCoV-2.

Desde o primeiro dia do mês de maio do ano de 2020, o remdesivir teve sua administração autorizada pela Food and Drug Administration (FDA) nos Estados Unidos, porém, o medicamento ainda se encontra em fases experimentais, por isso não há aprovação formal por parte da FDA. Seu uso apenas foi autorizado em decorrência da situação pandêmica vivida pelo mundo devido à COVID-19.

Contudo, o medicamento deve ser administrado somente em ambiente hospitalar, por profissionais de 
saúde capacitados para os pacientes infectados pelo SARSCoV-2 em estado grave e crítico e, além disso, devem estar em condições de receber administração parenteral da medicação, mesmo porque o remdesivir só pode ser prescrito por via intravenosa.

Atualmente, não há um consenso a respeito do tempo ideal de tratamento. Nos Estados Unidos, as autoridades em saúde sugerem um período de 5 a 10 dias, a depender da gravidade do caso.

A particularidade positiva encontrada com a administração do antiviral remdesivir é a redução em quatro dias do tempo de internação.

\section{Nitazoxanida}

A nitazoxanida é um anti-helmíntico de amplo espectro, com elevada atividade antiviral. O fármaco é utilizado no Brasil há mais de uma década para o tratamento de doenças parasitárias e virais intestinais.

Estudos realizados em humanos já confirmaram sua eficácia contra o vírus influenza, um microrganismo tipicamente respiratório, em regimes diferentes dos habitualmente prescritos, porém, devido à superioridade do oseltamivir, a nitazoxanida não foi administrada para tal finalidade.

O fármaco em questão possui garantia de eficácia, segurança, qualidade e biodisponibilidade em diferentes regimes posológicos e doses, e pode ser utilizado por crianças, adultos, e também por idosos. Os efeitos colaterais não são relevantes do ponto de vista global, de tal forma que a reação adversa comumente encontrada é a coloração amarelo-esverdeada de secreções, principalmente a urina. 
A ideia da primeira fase da pesquisa é realizar um estudo randomizado duplo-cego com pacientes em estado moderado da infecção pelo novo coronavírus. Um estudo duplo-cego significa que nem o profissional de saúde, nem o paciente sabem se estão recebendo o medicamento ou o placebo.

Os pacientes considerados inclusos nesse estudo devem possuir resultado positivo para o SARS-CoV-2 ao exame da reação em cadeia da polimerase em tempo real (RT-PCR). Além disso, eles devem estar em estado moderado da infecção, ou seja, apresentarem febre, tosse, indisposição e insuficiência respiratória, porém, sem necessidade do uso de ventilação mecânica.

Portanto, até o momento, apesar de os estudos in vitro demonstrarem eficácia da nitazoxanida na inibição do SARS-CoV-2, isso não significa que os estudos in vivo terão os mesmos resultados.

Há estudos, também, acerca da utilização de anticorpos produzidos por pacientes já recuperados da infecção pelo vírus da COVID-19, como o realizado aqui no Brasil pelos hospitais Israelita Albert Einstein, Sírio-Libanês e a Universidade de São Paulo (USP). Nessa pesquisa, é coletado o sangue de indivíduos que estiveram infectados para a retirada do plasma (parte líquida do sangue) contendo anticorpos específicos contra o novo coronavírus. Estudos na mesma linha pesquisam a retirada de células da medula óssea responsáveis pela defesa contra o SARS-CoV-2 de pacientes recuperados da enfermidade. Essa modalidade de tratamento ainda carece de dados confirmatórios para a sua aprovação formal contra a COVID-19. 
Para finalizar, nas atuais circunstâncias, todo o mundo busca urgentemente um tratamento efetivo para a COVID-19, vários ensaios clínicos estão em andamento e, até o momento, têm-se, pelo menos doze possiveis tratamentos potenciais para a COVID-19. 


\section{REFERÊNCIAS}

BRASIL. Ministério da Saúde. Secretaria de Atenção Especializada à Saúde. Departamento de Atenção Hospitalar, Domiciliar e de Urgência. Protocolo de manejo clínico da Covid-19 na Atenção Especializada [recurso eletrônico]/ Ministério da Saúde, Secretaria de Atenção Especializada à Saúde, Departamento de Atenção Hospitalar, Domiciliar e de Urgência. 1. ed. rev. Brasília: Ministério da Saúde, 2020. Disponivel em: <https://phila.nescon.medicina.ufmg.br/source/ covid_19_caso1/introducao/documentos/protocolo_ manejo_clinico_Covid19_atencao_especializada.pdf>. Acesso em: 7 jun. 2020.

BRASIL. Ministério da Saúde. Secretaria de Vigilância em Saúde. Departamento de Vigilância das Doenças Transmissiveis. Protocolo de tratamento de Influenza: 2017 [recurso eletrônico] / Ministério da Saúde, Secretaria de Vigilância em Saúde, Departamento de Vigilância das Doenças Transmissiveis. - Brasilia : Ministério da Saúde, 2018. Disponivel em: <https://bvsms.saude.gov.br/bvs/ publicacoes/protocolo_tratamento_influenza_2017. pdf>. Acesso em: 7 jun. 2020.

CENTRO DE CONTROLE E PREVENÇÃO DE DOENÇAS. Coronavirus Disease 2019 (COVID-19): Cases in the U.S. Updated February 5, 2020. Disponivel em: <https://www. cdc.gov/coronavirus/2019-ncov/cases-in-us.html>. Acesso em: 7 jun. 2020.

CHEN, J.; et. al. A pilot study of hydroxychloroquine in treatment of patients with common coronavirus 
disease-19 (COVID-19), Journal of Zhejiang University

(Medical Science), Zejiang, China, vol. 49, 2. ed., p. 215219. Disponivel em: <http://www.zjujournals.com/med/ EN/10.3785/j.issn.1008-9292.2020.03.03\#>. Acesso em: 7 jun. 2020.

CHEN, N.; et al. Epidemiological and clinical characteristics of 99 cases of 2019 novel coronavirus pneumonia in Wuhan, China: a descriptive study. Lancet, Londres, 15-21 jan. 2020. Disponivel em: <https://www. thelancet.com/journals/lancet/article/PIISO14O6736(20)30211-7/fulltext>. Acesso em: 7 jun. 2020.

FERNANDES, G. DE O. R.; et al. Efeitos farmacológicos decorrentes ao bloqueio dos receptores AT1. Revista Científica da Faculdade de Educação e Meio Ambiente, vol. 8, n. 2, p. 139-150, 15 dez. 2017. Disponivel em: <http://www.faema.edu.br/revistas/index.php/RevistaFAEMA/article/view/588>. Acesso em: 7 jun. 2020.

FINTELMAN-RODRIGUES, N.; et al. Atazanavir inhibits SARS-CoV-2 replication and pro-inflammatory cytokine production. bioRxiv, 6 abr. 2020. Disponivel em: <https:// doi.org/10.1101/2020.04.04.020925>. Acesso em: 7 jun. 2020.

GAUTRET, P.; et al. Hydroxychloroquine and azithromycin as a treatment of COVID-19: results of an open-label non-randomized clinical trial. International Journal of Antimicrobial Agents, 20 mar. 2020. Disponivel em: <https://www.sciencedirect.com/science/article/pii/ Sog24857920300996>. Acesso em: 7 jun. 2020.

KONG, W.; AGARWAL, P.P. Chest Imaging Appearance of COVID-19 Infection Weifang Kong. Radiology: 
Cardiothoracic Imaging, vol. 2, n. 1, 13 fev. 2020.

Disponivel em: <https://pubs.rsna.org/doi/10.1148/ ryct.2020200028>. Acesso em: 7 jun. 2020.

KUPFERSCHMIDT, K.; COHEN, J. Race to find COVID19 treatments accelerates. Science, vol. 367, ed. 6485, p. 1412-1413, 27 mar. 2020. Disponivel em: <https://science. sciencemag.org/content/367/6485/1412.full>. Acesso em: 7 jun. 2020.

MINISTÉRIO DA SAÚDE. Diretrizes para

Diagnóstico e Tratamento da COVID-19. 2. ed. 8 abr. 2020. Disponivel em: <https://phila.nescon.medicina. ufmg.br/source/covid_19_caso1/introducao/ documentos/diretrizes_diagnostico_tratamento_covid19. pdf>. Acesso em: 7 jun. 2020.

MINISTÉRIO DA SAÚDE. Diretriz Nacional de Assistência ao Parto Normal: relatório. Brasília. Comissão Nacional de Incorporação de Tecnologias no SUS - CONITEC; Jan. 2016. Disponivel em: <http://conitec.gov.br/images/ Consultas/2016/Relatorio_Diretriz-PartoNormal_CP.pdf>. Acesso em: 7 jun. 2020.

MINISTÉRIO DA SAÚDE. Nota Informativa N 6/2020DAF/SCTIE/MS. $1^{\circ}$ abr. 2020. Departamento de Assistência Farmacêutica e Insumos Estratégicos - DAF. Disponivel em: <https://phila.nescon.medicina.ufmg.br/ source/covid_19_caso1/introducao/documentos/nota_ informativa06_2020_DAF_SCTIE.pdf>. Acesso em: 28 abr. 2020.

MINISTÉRIO DA SAÚDE. Protocolo de Manejo Clínico do Coronavírus na Atenção Primária à Saúde. ed. 7. Brasília: Secretaria de Atenção Primária à Saúde (SAPS)/ 
Ministério da Saúde, abr. 2020. Disponivel em: <https:// phila.nescon.medicina.ufmg.br/source/covid_19_caso1/ introducao/documentos/protocolo_manejo_clinico_ coronavirus_atencaoPrimaria.pdf>. Acesso em: 7 jun. 2020.

NG, J.J.; et al. The Global Impact of COVID-19 on Vascular Surgical Services, Journal of Vascular Surgery, vol. 71, ed. 6, jun. 2020, p. 2182-2183. Disponivel em: <https:// pubmed.ncbi.nlm.nih.gov/32247029>. Acesso em: 7 jun. 2020.

ORGANIZAÇÃO MUNDIAL DA SAÚDE. CID-10:

Classificação Internacional de Doenças. 2020. Disponivel em: <https://icd.who.int/en>. Acesso em: 7 jun. 2020.

ORGANIZAÇÃO MUNDIAL DA SAÚDE. WHO

recommendations: intrapartum care for a positive childbirth experience. Geneva: World Health Organization; 2018.

ORGANIZAÇÃO MUNDIAL DA SAÚDE. World Health Organization: Novel Coronavirus (2019-nCoV) Situation report. 4 fev. 2020. Disponivel em: <https://www.who. int/docs/default-source/coronaviruse/situationreports/20200204-sitrep15-ncov.pdf?sfvrsn=88fe8ad6>. Acesso em: 7 jun. 2020.

SANDERS, J.M.; et al. Pharmacologic Treatments for Coronavirus Disease 2019 (COVID-19). JAMA, vol. 323, ed. 18, 13 abr. 2020,p. 1824-1836. Disponível em: <doi:10.1001/ jama.2020.6019>. Acesso em: 7 jun. 2020

SHEN, L.W.; MAO, H.J.; WU, Y.L.; et al. TMPRSS2: A potential target for treatment of influenza virus and coronavirus infections. Biochimie, vol. 142, 2017, p. 1-10. Disponivel em: 
<https://pubmed.ncbi.nlm.nih.gov/28778717>. Acesso em: 7 jun. 2020.

TAISHENG, L.; HONGZHOU, L.; WENHONG, Z. (2020)

Clinical observation and management of COVID-19

patients, Emerging Microbes \& Infections, vol. 9, ed. 1, p. 687-690, 2020. Disponivel em: <https://doi.org/10.1080/ 22221751.2020.1741327>. Acesso em: 7 jun. 2020. 


\section{SOBRE OS AUTORES}

\section{Carlos Eduardo Coradassi}

Médico Veterinário

Doutor em Saude Única-UFPR

Professor Adjunto do Departamento de Enfermagem e Saúde Pública da UEPG

\section{Fabiana Postiglione Mansani}

Farmacêutica e Bioquímica

Doutora em Ciências Bioquímicas-UFPR e Universidade de Coimbra

Professora Associada do Departamento de Medicina da UEPG

\section{Felício de Freitas Netto}

Curso de Medicina

Interno do Curso de Medicina da UEPG

\section{Gabriela Benassi}

Curso de Medicina

Interna do Curso de Medicina da UEPG 


\section{Lislei Teresinha Preuss}

Assistente Social

Doutora em Serviço Social - PUC/RS

Professora Adjunta do Departamento de Serviço Social da UEPG

\section{Pollyanna Kássia de Oliveira Borges}

Cirurgiã-dentista

Doutora em Saúde Coletiva-UNIFESP

Professora Associada do Departamento de Enfermagem e Saúde Pública da UEPG

\section{Ricardo Zanetti Gomes}

Médico

Doutor em Clínica Cirúrgica-UFPR

Professor Associado do Departamento de Medicina da UEPG 